\title{
Trends and determinants of condomless sex in gonorrhoea patients diagnosed in France through the sentinel surveillance network ResIST, 2005-2014
}

Oche Adam Itodo ${ }^{1}$, Delphine Viriot ${ }^{1}$, Annie Velter ${ }^{1}$, Lucie Leon ${ }^{1}$, Nicolas Dupin², Beatrice Bercot ${ }^{3}$, Agathe Goubard ${ }^{4}$, François Lassau ${ }^{5,6}$, Sébastien Fouere ${ }^{5}$, Pervenche Martinet ${ }^{7}$, William Tosini ${ }^{8}$, Sophie Florence ${ }^{9}$, Referents for the Regional Offices of the French National Public Health Agency (Santé Publique France), Florence Lot ${ }^{1}$ and Ndeindo Ndeikoundam Ngangro ${ }^{1 *}$

\begin{abstract}
Background: Gonorrhoea is increasing in France since its resurgence in the late 1990's. Understanding trends of condomless sex is a requirement to tailor prevention toward most exposed individuals. This study aims to analyse trends and determinants of condomless penetrative sex (PS) in MSM and heterosexuals diagnosed with gonorrhoea in France.
\end{abstract}

Methods: A standardized self-administered questionnaire filled by 3453 patients was used to monitor condomless sex through the sentinel surveillance network ResIST between 2005 and 2014. Trends were used to describe consistent condom use for penetrative sex (PS). A logistic regression model analysed patients' characteristics associated with condomless PS.

Results: Between 2005 and 2014, condomless PS increased regardless of sexual orientation. Condomless PS was particularly common among HIV positive men who have sex with men (MSM (65\%)). People living in metropolitan regions outside Paris area (adjusted odds-ratio (AOR) $[95 \% \mathrm{CI}]=1.33[1.12-1.58]$ ) were more likely to engage in condomless PS. Conversely, MSM (AOR [95\% Cl] $=0.21$ [0.16-0.29]), HIV seronegative patients (AOR [95\% Cl] $=0.68$ $[0.51-0.89])$, patients diagnosed in hospital (AOR $[95 \% \mathrm{Cl}]=0.66[0.45-0.97])$ and multi-partners $(\geq 10$ partners, AOR $[95 \% \mathrm{Cl}]=0.54[0.40-0.74])$ were more likely to use condoms.

Conclusions: These findings highlight a decreasing use of condom in MSM and heterosexuals diagnosed with gonorrhoea. Prevention strategies should take in account drivers of condomless sex in a context of uncontrolled STI epidemics.

Keywords: Gonorrhoea, France, MSM, Surveillance, Sexual behaviour

\footnotetext{
* Correspondence: ndeindo.ndeikoundam@santepubliquefrance.fr

'Santé Publique France (The French National Public Health Agency), Saint Maurice, France

Full list of author information is available at the end of the article
}

(c) The Author(s). 2020 Open Access This article is licensed under a Creative Commons Attribution 4.0 International License, which permits use, sharing, adaptation, distribution and reproduction in any medium or format, as long as you give appropriate credit to the original author(s) and the source, provide a link to the Creative Commons licence, and indicate if changes were made. The images or other third party material in this article are included in the article's Creative Commons licence, unless indicated otherwise in a credit line to the material. If material is not included in the article's Creative Commons licence and your intended use is not permitted by statutory regulation or exceeds the permitted use, you will need to obtain permission directly from the copyright holder. To view a copy of this licence, visit http://creativecommons.org/licenses/by/4.0/ The Creative Commons Public Domain Dedication waiver (http://creativecommons.org/publicdomain/zero/1.0/) applies to the data made available in this article, unless otherwise stated in a credit line to the data. 


\section{Background}

In France, gonorrhoea has continued to rise since its resurgence in the late 1990's [1]. Considering its complications such as salpingitis, ectopic pregnancy, pelvic inflammatory disease, infertility, its role in HIV transmission and the threat of antibiotic resistance, gonorrhoea is considered a public health concern [2-5]. Moreover, asymptomatic infections contribute to its spread.

In France, 15,100 cases were biologically confirmed in 2012 with a rate of 39 per 100,000 for people aged 15 to 59 years [6]. National surveillance data show that gonorrhoea primarily spread between men who have sex with men (MSM) [1].

With its short incubation of 2 to 5 days [2], gonorrhoea diagnosis trends could serve as a proxy to analyse changes in sexual behaviour and sexually transmitted infection (STI) prevention. Thus, its spread probably reflects increasing condomless sex described by behavioural studies among MSM [7-13]. Nevertheless, to our knowledge, no study purposely analysed determinants of condom use in patients diagnosed with STI in France, particularly in heterosexuals. This study aims to analyse trends and determinants of condomless penetrative sex (PS) in MSM and heterosexuals diagnosed with gonorrhoea, by employing for the first time the continuous data of the national surveillance of gonorrhoea in France [1].

\section{Methods \\ Setting}

In France, the national surveillance of gonorrhoea relies on a sentinel network of clinicians, "ResIST", collecting demographic, clinical, biological and behavioural data [1]. During the study period (20052014), reported cases were mostly (99.6\%) diagnosed by physician working in free STI clinics (named CeGIDD in France) [1]. These facilities target mainly high risk groups and disadvantaged ones such as MSM and migrants from high incidence countries, while general population might visit primarily general practitioners or non-hospital specialists for STI concerns. Almost all reported cases were diagnosed in mainland regions, as the ResIST network participation is largely insufficient in the overseas regions excluded from these analyses [1]. The network has 116 STI clinics, 14 hospital services and 594 clinicians in 2018. In 2012, ResIST was estimated to cover $6.3 \%$ of gonorrhoea diagnoses in France [6].

\section{Case definition}

Gonorrhoea cases were bacteriologically defined through culture or nucleic acid amplification testing (NAAT) regardless anatomical location.

\section{Study population}

Gonorrhoea patients reported to the surveillance network between 2005 and 2014 and who completed a selfadministered structured behavioural questionnaire were the studied population.

\section{Data collection}

Doctors filled a questionnaire with demographic, clinical and biological information. Patients completed a structured questionnaire with information related to their sexual practices within the previous 12 months.

\section{Study variables}

Based on their reported sex and sexual practices, patients were categorized into groups of transmission; men who have sex with men (MSM), men who have sex with women exclusively (MSW), women who have sex with women (WSW) and women who have sex with men exclusively (WSM). Only one WSW was identified and subsequently removed from analyses. We classified the number of sexual partners in the last 12 months into sections ( 1 partner, 2 to 9 partners, 10 or more partners), as well as age ([14-20 years], [20-30 years], [30-40 years], [40-50 years], [50-60 years], and 60 years or over). Having steady (at least two sexual contact) or casual partner(s) (one sexual contact) in the last 12 months, knowledge about partners HIV status (positive, negative or unknown) for the last casual partner and all steady partners in last 12 months, HIV co-infection (positive, negative or unknown) were all variables of interest. Condomless sex defined as at least a condomless intercourse in the last 12 months, was ascertained for anal, vaginal and oral sex.

\section{Statistical analyses}

Patients' characteristics and sexual behaviour were described using proportions and median, for categorical and continuous variables respectively. Trends were used to analyse change across time, considering diagnosis centres reporting at least one case yearly over the last 3 years to take in account the fluctuation of centres' participation in ResIST [1]. Then quantitative variables were compared using the non-parametric Wilcoxon and Kruskal-Wallis tests whereas categorical variables were compared using the Fisher's exact test to assess association.

Using condomless penetrative sex whether anal or vaginal (PS) as an outcome, we carried out univariate and bivariate analyses after adjusting for the sexual orientation (MSM versus MSW and WSM) and HIV status since surveillance data demonstrated substantial differences in the way sexually transmitted infections (STI) spread considering these determinants [1]. Then, a logistic regression 
model was fitted to assess association between condomless PS and variables identified through the uni/bivariate analyses. All variables with $p \leq 0.20$ were included in the model and backward selected according to the Hosmer and Lemeshow approach. The significance level was set at $p<0.05$. Interactions (sexual orientation and HIV status) were tested in order to expand understanding of the relationships among variables but results were not included. Age was incorporated using fractional polynomials. Missing data were preserved during all analyses performed with Stata 12.1.

\section{Ethical approval}

ResIST network was approved by the French Personal Data Protection Authority (CNIL authorization 902, 057). "All procedures performed in studies involving human participants were in accordance with the ethical standards of the institutional and/or national research committee and with the 1964 Helsinki declaration and its later amendments or comparable ethical standards."

\section{Informed consent}

"Informed consent was obtained from all individual participants included in the study."

\section{Results}

\section{Population}

Between 2005 and 2014, 3453 (66.0\%) patients reported with gonorrhoea completed a self-administered behavioural questionnaire (Fig. 1). They were more frequently men $(82 \%$ versus $80 \%, p=0.038)$, MSM (55.7\% versus $43 \%, p<0.001)$ and diagnosed in hospitals $(3.9 \%$ versus $1 \%, p<0.001)$, compared to patients who did not fill this questionnaire. During the study period, the proportion of women, notably WSM, increased from 3.3 to $21 \%$ among patients reported to

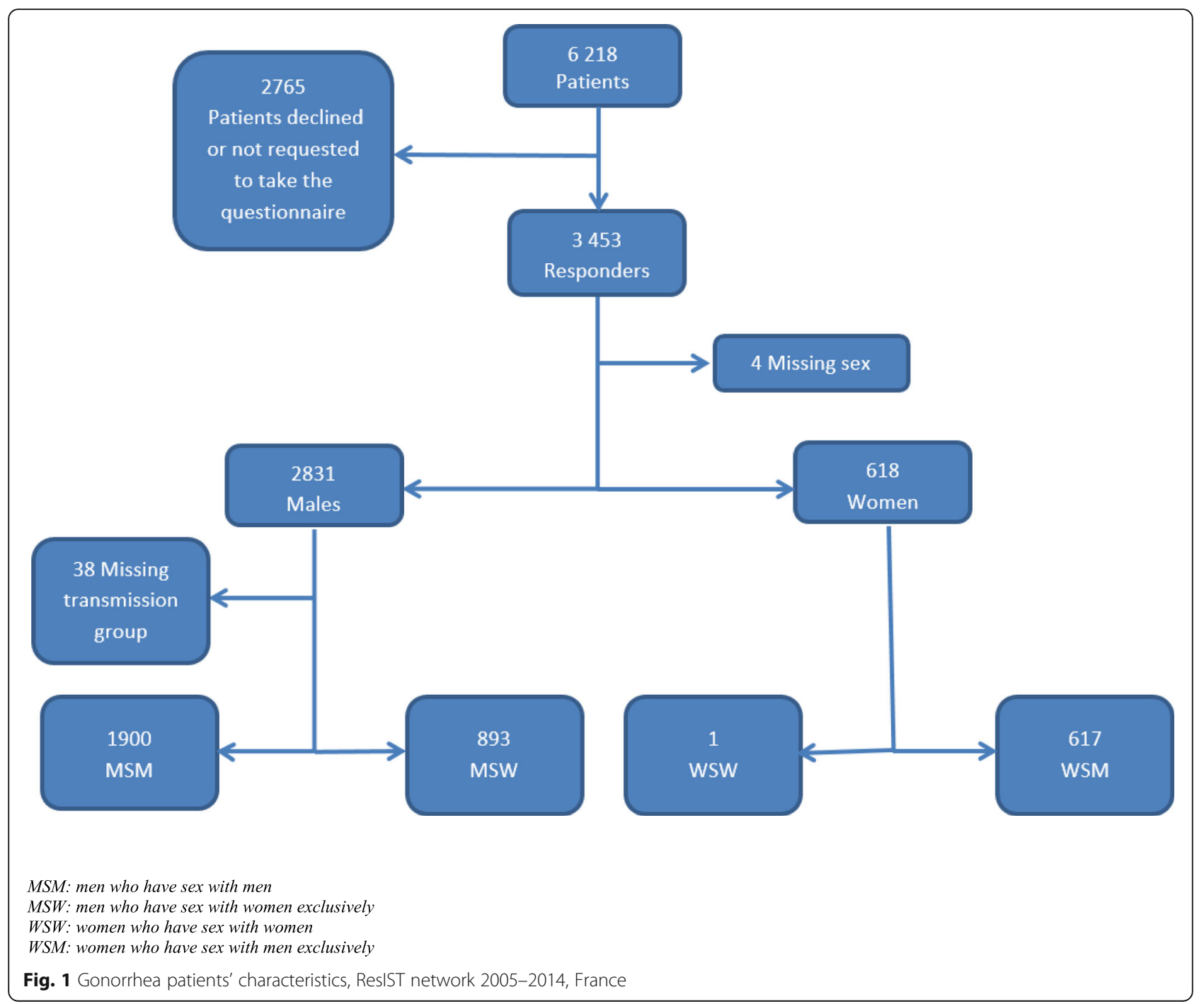


Table 1 Characteristics of respondent gonorrhoea patients to the behavioral questionnaire by transmission groups. ResIST network 2005-2014, France

\begin{tabular}{|c|c|c|c|}
\hline & $\begin{array}{l}\text { MSM } \\
N=1900\end{array}$ & $\begin{array}{l}\text { MSW } \\
N=893\end{array}$ & $\begin{array}{l}\text { WSM } \\
N=616\end{array}$ \\
\hline \multicolumn{4}{|l|}{ Age class (\%) } \\
\hline 14-20 years & $103(5.4)$ & $80(9.0)$ & $185(30)$ \\
\hline 20-30 years & $949(49.9)$ & $544(60.9)$ & $351(57)$ \\
\hline 30-40 years & $488(25.7)$ & $149(16.7)$ & $57(9.3)$ \\
\hline $40-50$ years & $234(12.3)$ & $62(6.9)$ & $14(2.3)$ \\
\hline $50-60$ years & $81(4.3)$ & $26(2.9)$ & $4(0.6)$ \\
\hline $60+$ years & $31(1.6)$ & $17(1.9)$ & $0(0.0)$ \\
\hline Missing & $14(0.7)$ & $15(1.7)$ & $5(0.8)$ \\
\hline \multicolumn{4}{|l|}{ Region of residence (\%) } \\
\hline Paris region & $695(36.6)$ & $268(30.0)$ & $118(19.2)$ \\
\hline Other metropolitan regions & $1109(58.4)$ & $540(60.5)$ & $454(73.7)$ \\
\hline Missing & $96(5.1)$ & $85(9.5)$ & $44(7.1)$ \\
\hline \multicolumn{4}{|l|}{ Country of birth (\%) } \\
\hline France & $1510(79.5)$ & $603(67.5)$ & $487(79.1)$ \\
\hline Other European countries & $98(5.2)$ & $19(2.1)$ & $19(3.1)$ \\
\hline Non-European countries & $209(11.0)$ & $223(25.0)$ & $84(13.6)$ \\
\hline Missing & $83(4.4)$ & $48(5.4)$ & $26(4.2)$ \\
\hline \multicolumn{4}{|l|}{ Motive for consultation (\%) } \\
\hline Genital signs of STI & $1283(67.5)$ & $760(85.1)$ & $210(34.1)$ \\
\hline Partner with STI & $169(8.9)$ & $39(4.4)$ & $132(21.4)$ \\
\hline Routine testing & $227(11.9)$ & $41(4.6)$ & $149(24.2)$ \\
\hline Other clinical signs & $62(3.3)$ & $11(1.2)$ & $38(6.2)$ \\
\hline Missing & $159(8.4)$ & $42(4.7)$ & $87(14.1)$ \\
\hline \multicolumn{4}{|l|}{ Presence of symptoms (\%) } \\
\hline Yes & $1352(71.2)$ & $803(90.0)$ & $328(53.2)$ \\
\hline No & $545(28.7)$ & $87(9.7)$ & $285(46.3)$ \\
\hline Missing & $3(0.2)$ & $3(0.3)$ & $3(0.5)$ \\
\hline \multicolumn{4}{|l|}{ HIV serologic status (\%) } \\
\hline Newly diagnosed & $20(1.1)$ & $7(0.8)$ & $1(0.2)$ \\
\hline Known seropositivity & $244(12.8)$ & $13(1.5)$ & $0(0.0)$ \\
\hline Negative & $1482(78.0)$ & $766(85.8)$ & $556(90.3)$ \\
\hline Missing & $154(8.1)$ & $107(12.0)$ & $59(9.6)$ \\
\hline
\end{tabular}

MSM men who have sex with men, MSW men who have sex with women exclusively, WSM women who have sex with men exclusively

the ResIST network. The proportion of $40-50$ years olds decreased from 15 to $9 \%$. The proportion of of people living with HIV remains steady over the time as $12 \%$.

There were $26.2 \%$ MSW and $18.1 \%$ WSM among participants. Median age for MSM (28 years) patients was higher than for heterosexual males (25 years) and heterosexual females (21 years) $(p<0.0001)$. People aged between 20 and 30 years represented more than half of the study population (Table 1). The majority $(76.2 \%)$ of the patients were born in France. Most patients were symptomatic at the time of gonorrhoea diagnosis: heterosexual men (90.0\%), MSM (71.2\%) and heterosexual females (53.3\%) $(p<$ $0.001)$. STI symptoms were the main motivation for seeking healthcare $(67.5 \%$ in MSM, $85.2 \%$ in heterosexual men and $34.2 \%$ in heterosexual women) while suspected STI in a sexual partner and routine testing were frequently reported by women (21.4 and 24.2\%) compared to men (respectively 8.9 and 12\% MSM and 4.4 and $4.6 \%$ heterosexual men, $p<0.001$ ). HIVcoinfection level remained high for MSM (13.9\% versus $2.3 \%$ heterosexual men and $0.2 \%$ heterosexual women, $p<0.001)$.

\section{Sexual behaviours}

In the last 12 months preceding the gonorrhoea diagnosis, MSM reported a median number of 10 sexual partners which remained steady during the surveillance period (Table 2). A median of 4 sexual partners was observed for heterosexual males and females within this same period. A higher proportion of heterosexual patients $(70.7 \%$ of men and $81.9 \%$ of women versus $63.2 \%$ of MSM) reported steady partner(s) and majority of heterosexual men (79.7\%) and MSM (89.4\%) had casual partner(s) compared to heterosexual women (49.6\%). Quarter of heterosexual women (28.4\%) and 15.8\% heterosexual men were unaware of their steady partners HIV status compared to a lower proportion of MSM (6.5\%). Conversely, majority of MSM (56.7\%) and heterosexual men $(51.5 \%)$ were unaware of their casual partners HIV status. Half of heterosexual women did not answer this question while $29.2 \%$ also ignore casual partner HIV status.

Between 2005 and 2014, a significant decline in the consistant use of condoms for PS was observed whether patients were MSM (from 51.9 to $39.3 \%, p<$ 0.001 ) or heterosexuals (from 22.5 to $17.1 \%, p=$ 0.005) despite a slight increase observed from 2012 to 2014 in MSM and from 2013 to 2014 in heterosexuals (Fig. 2). Condom use for PS with casual (61.1\%) or steady (25.1\%) partner(s) remained higher among MSM compared to heterosexuals (respectively 40.1 and $21.4 \%$ men, 28.0 and $22.4 \%$ women, $p<0.01$ ) during the study period (Table 2). Nevertheless, considering specifically anal sex, $60.7 \%$ of MSM did not use condoms systematically $(p<0.01)$. Majority of heterosexuals $(77.3 \%$ men and $88.3 \%$ women) did not consistently protect their vaginal intercourse $(p=0.001)$.

Furthermore, condom use for oral sex with casual and steady partners was not frequent, whether patients were MSM (5.8 and 3.6\%), MSW (8.0 and 5.0\%) or WSM (5.2 and 2.9\%). A higher proportion of MSM reported no 
Table 2 Sexual behaviours of patients diagnosed with gonorrhoea in the last 12 months. ResIST network 2005-2014, France

\begin{tabular}{|c|c|c|c|}
\hline & MSM & MSW & WSM \\
\hline \multicolumn{4}{|c|}{ Number of partners (\%) } \\
\hline 1 partner & $132(7.0)$ & $121(13.6)$ & $157(25.5)$ \\
\hline 2 to 9 partners & $748(39.4)$ & $537(59.5)$ & $403(64.8)$ \\
\hline 10 partners or more & $924(49.2)$ & $185(21.4)$ & $37(6.7)$ \\
\hline Missing & $86(4.53)$ & $50(5.6)$ & $19(3.1)$ \\
\hline \multicolumn{4}{|c|}{ Systematic condom use for anal sex (\%) } \\
\hline Yes & $701(36.9)$ & $166(18.6)$ & $26(4.2)$ \\
\hline No & $1154(60.7)$ & $356(39.9)$ & $171(27.8)$ \\
\hline Missing & $45(2.4)$ & $371(41.5)$ & $419(68.0)$ \\
\hline \multicolumn{4}{|c|}{ Systematic condom use for vaginal sex (\%) } \\
\hline Yes & & $159(17.8)$ & $48(7.8)$ \\
\hline No & N.A & $690(77.3)$ & $544(88.3)$ \\
\hline Missing & & $44(4.9)$ & $24(3.9)$ \\
\hline \multicolumn{4}{|c|}{ Systematic condom use for oral sex (\%) } \\
\hline Yes & $24(1.3)$ & $21(2.4)$ & $9(1.5)$ \\
\hline No & $1798(94.6)$ & $737(82.5)$ & $446(72.4)$ \\
\hline Missing & $78(4.1)$ & $135(15.1)$ & $161(26.1)$ \\
\hline \multicolumn{4}{|l|}{ Steady partner(s) (\%) } \\
\hline Yes & $1200(63.2)$ & $631(70.7)$ & $505(82.0)$ \\
\hline No & $682(35.9)$ & $262(29.3)$ & $105(17.0)$ \\
\hline Missing & $18(0.9)$ & $0(0.0)$ & $6(1.0)$ \\
\hline \multicolumn{4}{|c|}{ HIV status of steady partner(s) (\%) } \\
\hline Positive & $117(6.2)$ & $9(1.0)$ & $1(0.2)$ \\
\hline Negative & $941(49.5)$ & $464(52.0)$ & $314(51.0)$ \\
\hline Not known & $123(6.5)$ & $141(15.8)$ & $175(28.4)$ \\
\hline Missing & $719(37.8)$ & $279(31.2)$ & $126(20.5)$ \\
\hline \multicolumn{4}{|c|}{ Condom use with steady partner(s) for previous PS (\%) } \\
\hline Yes & $477(25.1)$ & $191(21.4)$ & $138(22.4)$ \\
\hline No & $628(33.1)$ & $391(43.8)$ & $346(56.2)$ \\
\hline Missing & $795(41.8)$ & $311(34.8)$ & $132(21.4)$ \\
\hline \multicolumn{4}{|c|}{ Condom use with steady partner(s) for previous oral sex (\%) } \\
\hline Yes & $68(3.6)$ & $45(5.0)$ & $18(2.9)$ \\
\hline No & $1095(57.6)$ & $484(54.2)$ & $344(55.8)$ \\
\hline Missing & $737(38.8)$ & $364(40.8)$ & $254(41.2)$ \\
\hline \multicolumn{4}{|l|}{ Casual partner(s) (\%) } \\
\hline Yes & $1698(89.4)$ & $712(79.7)$ & $305(49.5)$ \\
\hline No & $189(9.9)$ & $178(19.9)$ & $305(49.5)$ \\
\hline Missing & $13(0.7)$ & $3(0.3)$ & $6(1.0)$ \\
\hline \multicolumn{4}{|c|}{ Knowledge of HIV status of the last casual partner (\%) } \\
\hline Positive & $78(4.1)$ & $9(1.0)$ & $1(0.2)$ \\
\hline Negative & $517(27.2)$ & $226(25.3)$ & $117(19.0)$ \\
\hline Not known & $1077(56.7)$ & $460(51.5)$ & $180(29.2)$ \\
\hline Missing & $228(12.0)$ & $198(22.2)$ & $318(51.6)$ \\
\hline
\end{tabular}


Table 2 Sexual behaviours of patients diagnosed with gonorrhoea in the last 12 months. ResIST network 2005-2014, France (Continued)

\begin{tabular}{lccc}
\hline \multicolumn{1}{c}{ MSM } & MSW & WSM \\
\hline Condom use with casual partner(s) for the last PS (\%) & & $358(40.1)$ & $172(27.9)$ \\
Yes & $1160(61.1)$ & $299(33.5)$ & $121(19.6)$ \\
No & $334(17.6)$ & $236(26.4)$ & $323(52.4)$ \\
Missing & $406(21.4)$ & & $31(8.0)$ \\
Condom use with the casual partner(s) for the last oral sex (\%) & $524(58.7)$ & 179 (29.1) \\
Yes & $111(5.8)$ & $298(33.4)$ & $405(65.7)$ \\
No & $1527(80.4)$ & $262(13.8)$ & \\
Missing
\end{tabular}

MSM men who have sex with men, MSW men who have sex with women exclusively, WSM women who have sex with men exclusively

protection for their most recent oral sex with casual (80.4\%) partner(s) (Table 2).

\section{Patient's characteristics associated with condom use} The multivariable model (Table 3) shows that condomless sex was significantly less frequent among patients aged 30-50 years (adjusted odds-ratio (AOR) [95\% confidence interval $(95 \% \mathrm{CI})]=0.51[0.36-0.71]$ for $40-50$ year olds). People living in metropolitan regions outside Paris area (AOR $[95 \% \mathrm{CI}]=1.33[1.12-1.58]$ ) were more likely to engage in condomless PS. Condomless PS was common in patients diagnosed with gonorrhoea after 2011 (AOR [95\% CI] = 1.61 [1.25-2.09] in 2012) compared to patients diagnosed before. Conversely, condomless PS was less common among MSM (AOR [95\% CI] $=0.21[0.16-0.29]), \quad \mathrm{MSW} \quad(\mathrm{AOR} \quad[95 \% \mathrm{CI}]=0.40[0.29-$ $0.55]$ ), HIV negative patients (AOR $[95 \% \mathrm{CI}]=0.68$ [0.51-0.89]) and patients with unknown HIV status ([AOR $[95 \% \mathrm{CI}]=0.63[0.44-0.90])$. Condomless PS was also less usual in patients reporting multiple sexual partners (at least 10 partners in last 12 months: AOR [95\% $\mathrm{CI}]=0.54[0.40-0.74])$.

\section{Discussion}

\section{Condomless penetrative sex}

The surveillance data reveal a significant decrease in the use of condoms for PS among MSM and heterosexuals diagnosed with gonorrhoea in France from 2005 to 2014. These trends are consistent with repeated behavioural studies demonstrating increases in condomless anal intercourse among MSM in France [1]. Increasing trends of condomless anal sex were also described in high-Income Countries (United States, Australia, United Kingdom) for MSM, but also heterosexuals [9-19]. Despite prevention effort, the overall proportion of individuals using consistently condoms for PS during the last 12 months remains unsatisfactory whether patients were MSM or heterosexuals during the study period.

\section{Condomless oral sex}

Although oral sex is currently quite common in France, it remains mostly mostly unprotected for MSM, MSM and WSM [1, 12]. Furthermore, a decrease was observed in the use of condoms for oral sex. This insufficient use of condoms for oral sex has also been observed in other European countries, notably in the United Kingdom [20, 21]. Moreover, increasing frequency of condomless oral sex in France, especially among the younger generation [13], might become a concern considering the potential development of antimicrobial resistance (AMR) in the pharyngeal infections $[5,22]$.

\section{Condom use and HIV status}

HIV positive and negative patients seemed to be more and more reluctant to use condoms for PS, whether they were MSM or heterosexual. The uptake of antiretroviral therapy (ARV) might have changed sexual behaviours, by lowering the fear of HIV acquisition or spreading the belief that HIV infection is curable. Repeated behavioural surveys conducted in France might reflect this shifting perceptions and attitudes towards HIV with increases in condomless anal intercourses among MSM, whether they were seropositive for HIV or not [9-12]. This is also observed in individuals seeking HIV post-exposure prophylaxis (PEP) between 2006 and 2011 in Paris [13]. Studies conducted in high incomes countries confirm the same trend for unprotect anal intercourse, notably in HIVdiscordant partners $[13,16,18,19,23,24]$.

A potential effect of HIV pre-exposure prophylaxis (PrEP) was not analysed since PrEP was officially launched in France in 2016. Future years' data might give an insight of its impact on the use of condom and epidemiology of gonorrhoea. Indeed, expanding the range of HIV prevention tools could paradoxally be associated with increasing STI diagnoses in its beneficiaries; but PrEP consultations remain opportunities for regular screenings in core populations and consequently prevention to STI transmission for people not using condom $[18,25,26]$. 


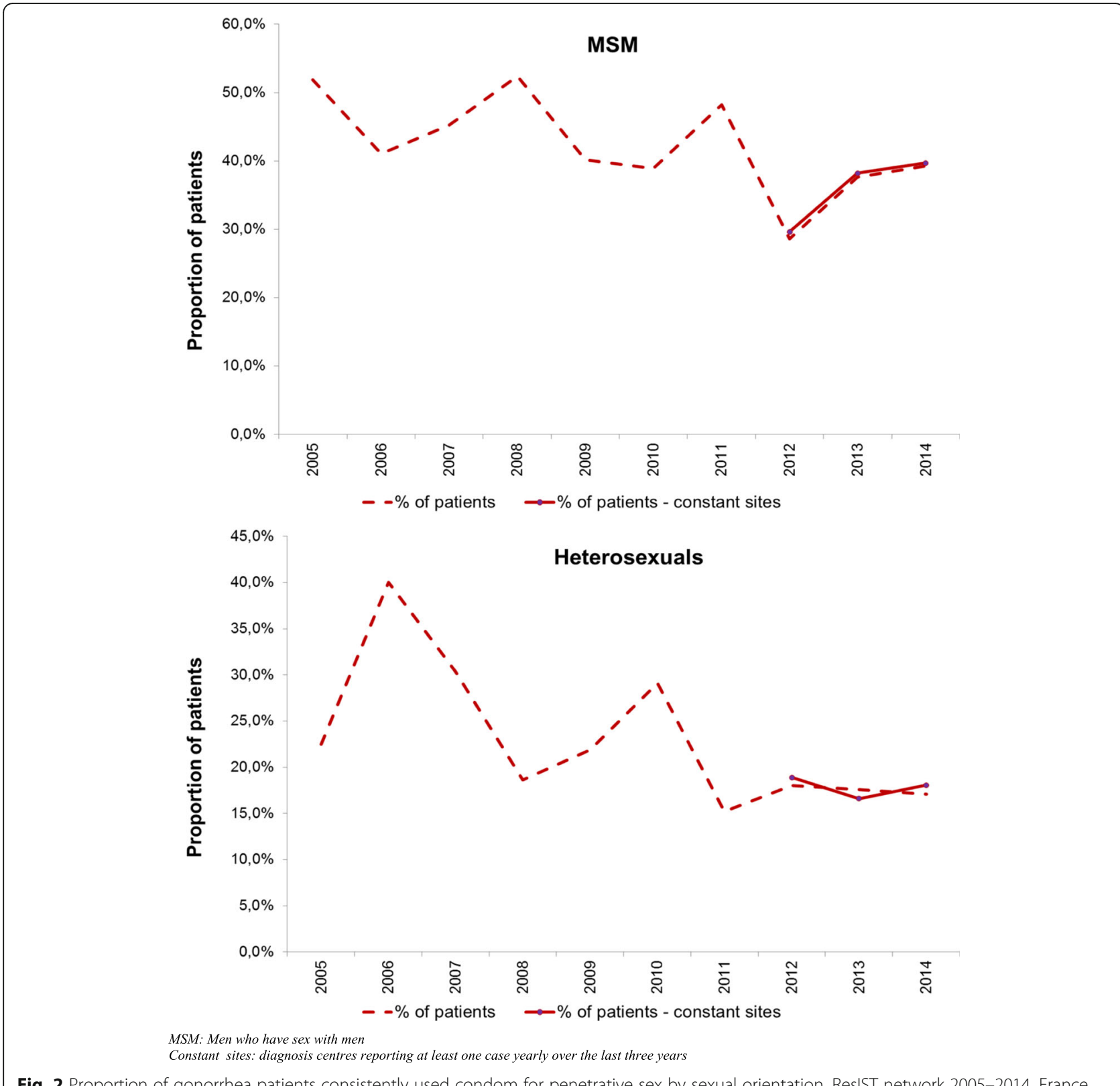

Fig. 2 Proportion of gonorrhea patients consistently used condom for penetrative sex by sexual orientation. ResIST network 2005-2014, France

\section{Patients characteristics associated with condomless penetrative sex}

The multivariate model demonstrates that gonorrhoea patients aged 14-20 years were more reluctant to use condom for PS compared to older ones, and especially the 30-50 years olds. Youth was already reported as a risk factor for condomless anal sex in MSM in France and in other European countries even if the level of condom use in general population remains higher among young people [11-13, 15, 19]. Nevertheless, these studies also reported declining trends in condom use for young population. Belonging to "post-AIDS (acquired immune-deficiency syndrome) generation and having an adventure-oriented sexuality" might explain the vulnerability of this population, notably during sexuality experimentation because of a less frightening perception of HIV infection thanks to antiretroviral and a better controlled epidemic compared to 1980 s and 1990s situation $[11-13,15,19]$. Nevertheless, even if condom use was more frequent above 20 years old, the model also shows a relatively close level of condom use among patients aged 50-60years and 20-40 years old. But the drivers of condom use might differ among generations and should be taken into account when designing preventive action $[9,10]$.

Condomless PS was not significantly associated with patiens'sex though it might reflect a gender based difficulty to negotiate condom use as well a mixed effect of 


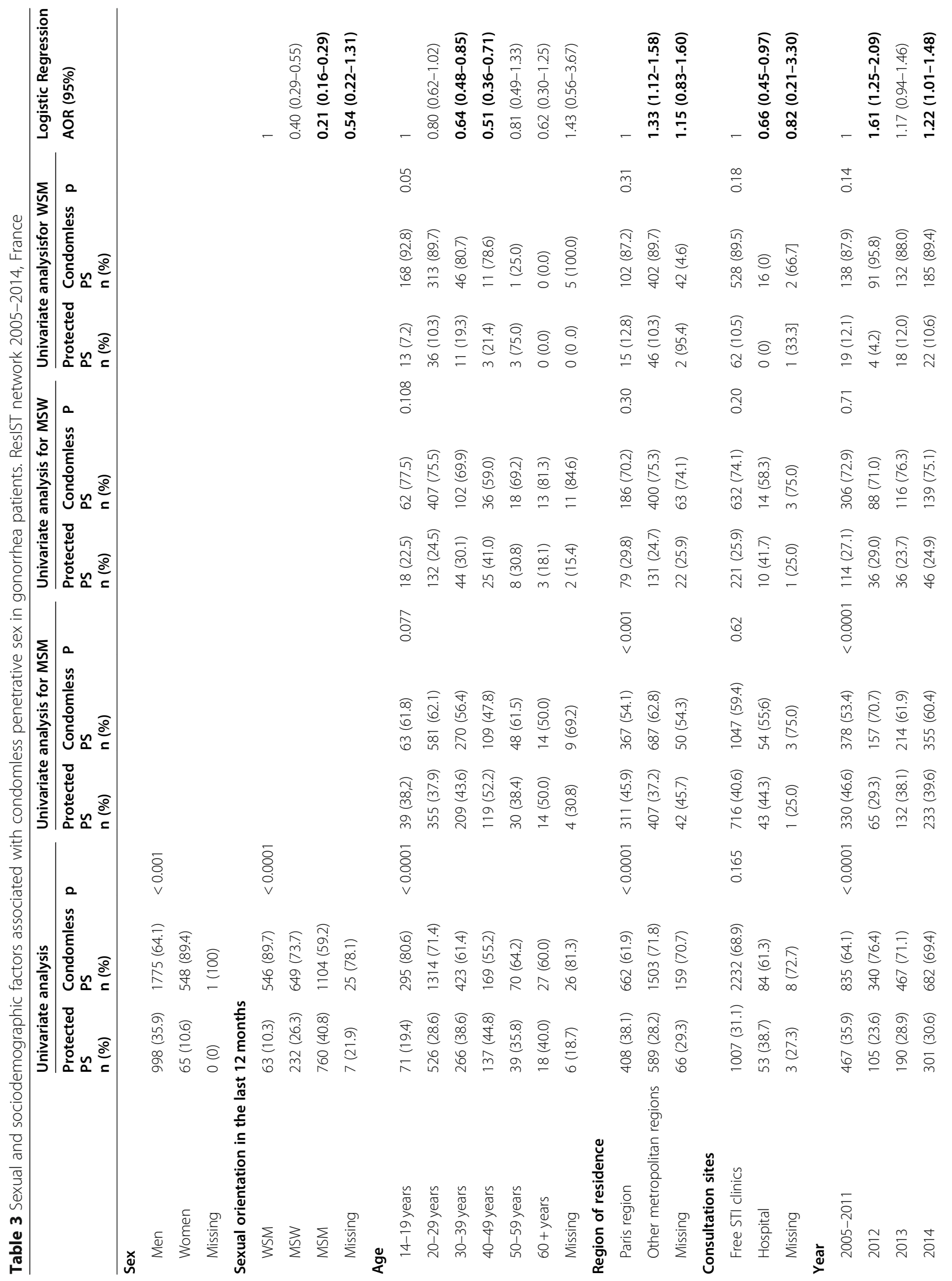




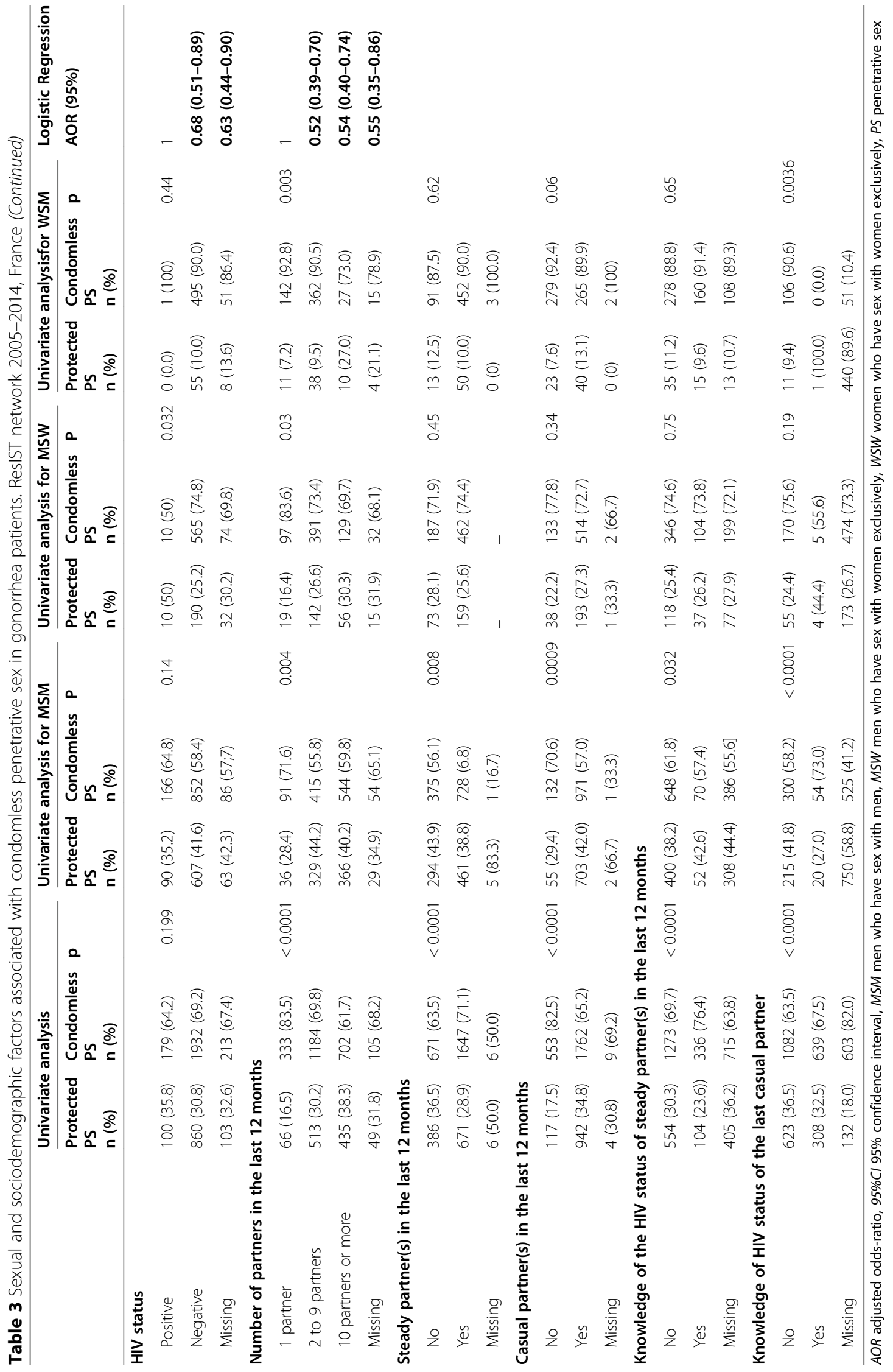


anal and vaginal penetration in the definition of PS used in the multivariable analyses [14]. Indeed, a study conducted in France, showed that women were more likely to be engaged in condomless sex [12].

Condomless PS was also significantly reported by patients diagnosed in other mainland regions compared to Paris area. A lower concentration or access to sexual health services in remotes or rural areas might explain this situation as well as delays and inequalities in prevention expansion within the geographic areas. Indeed, gonorrhoea resurgence started in Paris area in the early 2000 and then spread towards others regions. Prevention might have followed the same geographic pattern.

Moreover, patients diagnosed in a hospital based facilities were more likely to use condom than those diagnosed in free STI clinics. These results confirm that highly exposed populations are probably well targeted by free STI clinics, where systematic and opportunistic testing are applied whether patients are symptomatic or not [1]. Under representation of patients diagnosed by general practitioners in the ResIST sentinel (0.4\%) network probably hampered an accurate analysis of their behaviour. Cross sectional survey might give an insight of the situation in private medicine in France.

Gonorrhea diagnoses made after 2011 were significantly associated with condomless PS. It might reflect the rising trends of condomless anal penetration in MSM reported by behavioral studies in France [10, 11]. This prevention relapse is particularly concerning for HIV positive MSM, even if increasing risk was also reported by HIV negative MSM [10]. Nevertheless, the multivariate model demonstrates that patients seronegative for HIV were likely to use condom for PS. European results also demonstrate the same likelihood for seronegative MSM compared to seropositive ones, though HIV positive patients are mostly well sensitized [19]. Thus, retroviral treatments might shadow bacterial STI prevention among seropositive patients.

Multi-partnership over the last 12 months was associated with decreasing risk of condomless PS, suggesting a rising probability of using condom parallel to the number of sexual partners. Conversely, multi-partnership was reported in other contexts as a determinant of noncondom use. Qualitative studies conducted among STI patients or adjustment for additional sociodemographic variables (country of birth, education level, socioeconomic status ...), behavioural information (sero-adataptive behaviours, insertive/receptive position ...) and STI prevention/diagnosis access data (predisposing, enabling, needs and barriers factors) could enable further analyses.

\section{Limitations}

STI surveillance relying on a sentinel surveillance network, these results are neither exhaustive nor representative of the French population but they reflects the behavioural trends of MSM and heterosexuals exposed to gonorrhoea, then infected and mostly detected in the mainland's free STI clinics. Explored behaviours and determinants of condom use were limited by the surveillance constraints, notably the need to sustain a good level of participation. As gonorrhoea patients were almost exclusively reported by STI clinics (99\%), a crosssectional behavioural survey including private diagnostic centres, general practitioners and hospital units would give a complete picture of sexual behaviours trends in the general population, especially if health seeking behaviours, diagnosis delay, determinants of prevention use and additional behavioral information (i.e substance use ....) are collected. Moreover, reported patients are mainly symptomatic with frequent genital conditions, thus patients and especially MSM with asymptomatic pharyngeal and/or anal infections might need further behavioural analyses. Information on condom use for people that tested negative for gonorrhoea might help to monitor more accurately trends in condom use over time. Declarative information might over or underestimate some behaviours (e.g number of partner), because of social norms, desirability bias and recall bias. It was not possible to adjust analyses for repeated measurements per individual since anonymous identifier were not unique for patients and it was not possible to link patients throughout STI centers. Nevertheless, these surveillance data were the first to provide a continuous insight of sexual behaviours in highly exposed and infected MSM and heterosexual over the time.

\section{Conclusion}

In a context of uncontrolled STI epidemic, these continuous behavioral data confirmed in exposed, then infected and diagnosed gonorrhoea patients, a decreasing likelihood of condom use $[23,24]$ regardless sexual orientation. Considering sexuality, changes in social norms, and prevention availability and accessibility, repeated behavioural surveys including any type of STI diagnostic centre might contribute to a better understanding of patients' obstacles toward condom use and more largely difficulties to use prevention, compared to a standardized and continuous behavioural monitoring. Frequent screening remains the cornerstone to prevent STI transmission in core population not using condoms consistently.

\section{Abbreviations}

AIDS: Acquired ImmunoDeficiency Syndrome; AMR: Antimicrobial resistance; AOR: Adjusted odds-ratio; ARV: Antiretroviral therapy; HIV: Human

immunodeficiency virus; MSM: Men who have sex with men; MSW: Men who have sex with women exclusively; NAAT: Nucleic acid amplification testing; PEP: HIV post-exposure prophylaxis; PrEP: HIV pre-exposure prophylaxis; PS: Penetrative sex; STI: Sexually transmitted infections; WSW: Women who have sex with women exclusively 


\section{Acknowledgments}

We acknowledge all clinicians who contribute to the surveillance of STI through the ResIST sentinel network. We thank Corinne Pioche for her kind reviewing of the manuscript.

\section{Authors' contributions}

$\mathrm{OI}, \mathrm{DV}, \mathrm{AV}, \mathrm{FL}$ and NNN designed the study. OI, DV, LL and NNN performed the statistical analyses. OI, DV and NNN drafted the manuscript. OI, DV, AV, $L L, N D, B B, A G, F L, S F, P M, W T, S F, F L$ and NNN interpreted the data. ND, BB, $A G, F L, S F, P M, W T$, SF contributed to the manuscript. OI, DV, AV, LL, ND, BB, $A G, F L, S F, P M, W T, S F, F L$ and NNN revised and approved the manuscript.

\section{Funding}

Sante publique France (the French national public health agency) funded the national STI surveillance and coordinated data collection, analyses and writing of this manuscript.

\section{Availability of data and materials}

Access to the datasets used and/or analysed during the current study is restricted by the French Personal Data Protection Authority (CNIL authorization 902057). These data are available from the corresponding author on reasonable request.

\section{Ethics approval and consent to participate}

"All procedures performed in studies involving human participants were in accordance with the ethical standards of the institutional and/or national research committee and with the 1964 Helsinki declaration and its later amendments or comparable ethical standards." Verbal informed consent was obtained from all participants and parents/guardians for individuals under 16 years old with the approval of the French Personal Data Protection Authority (CNIL authorization 902057), the institutional review board (IRB) able to grant ethics approval for a study. According to French law, only "research organised and implemented on human beings in order to provide new medical or biological knowledge", as defined by article L. 1121-1 and article R. 1121-1 of the Code de la santé publique, are compelled to receive the approval of ethics committee such as the Committee of Protection of Persons (CPP). This study is only based on anonymous/pseudonymised data collected from health professionals for the purpose of public interest mission relating to health surveillance, mission entrusted to Sante publique France by the French Law (article L. 1413-1 code de la sante publique). Therefore, this study restricted to the national surveillance data did not meet the criteria for study "organised and implemented on human beings in order to provide new medical or biological knowledge," and did not require the approval of the CPP.

\section{Consent for publication}

"Not Applicable".

\section{Competing interests}

The authors declare that they have no conflict of interest.

\section{Author details}

${ }^{1}$ Santé Publique France (The French National Public Health Agency), Saint Maurice, France. ${ }^{2}$ French National Reference Centre for Bacterial STI (Syphilis), APHP, Cochin University Hospital, Paris, France. ${ }^{3}$ French National Reference Centre for Bacterial STI (Gonorhoae), APHP, Saint Louis University Hospital, Paris, France. ${ }^{4}$ Alfred Fournier Institute, Paris, France. ${ }^{5}$ Dermatology Department, AP-HP, Saint-Louis Hospital, Paris, France. ${ }^{6}$ Departmental Committee of Seine Saint Denis, Bobigny, France. ${ }^{7}$ Departmental Committee of Bouches-du-Rhônes, Marseille, France. ${ }^{8}$ STI Clinic (CeGIDD), Alfred Fournier Institute, Paris, France. ${ }^{9}$ Sexual Health Centre Figuier, Paris, France.

\section{Received: 15 January 2020 Accepted: 14 October 2020}

\section{Published online: 28 October 2020}

\section{References}

1. Ngangro NN, Viriot D, Fournet N, De Barbeyrac B, Gourbard A, Dupin N, et al. Bacterial sexually transmitted infections in France: recent trends and patients' characteristics in 2016. Euro Surveill. 2019;24(5):1800038.

2. Pilly E. Maladies Infectieuses et Tropicales. Paris: Vivactus Plus; 2010. p. 580.
3. Gottlieb SL, Low N, Newman LM, Bolan G, Kamb M, Broutet N. Toward global prevention of sexually transmitted infections (STIS): the need for STI vaccines. Vaccine. 2014;32(14):1527-35.

4. World Health Organization. Global health sector strategy on sexually transmitted infections 2016-2021. Geneva: World Health Organization; 2016. MS: WHO/RHR/16.09.

5. La Ruche G, Goubard A, Berçot B, Cambau E, Semaille C, Sednaoui P. Trends of antibiotic resistance of Neisseria gonorrhoeae in France, from 2001 to 2012. Bull Epidémiol Hebd. 2014;5:93-103.

6. La Ruche G, Le Strat Y, Fromage M, Berçot B, Goubard A, de Barbeyrac B, et al. Incidence of gonococcal and chlamydial infections and coverage of two laboratory surveillance networks, France, 2012. Euro Surveill. 2015;20(32):1-10.

7. Spauwen LW, Niekamp AM, Hoebe CJ, Dukers-Muijrers NH. Drug use, sexual risk behaviour and sexually transmitted infections among swingers: a crosssectional study in the Netherlands. Sex Transm Infect. 2015;91(1):31-6.

8. Folch C, Fernández-Dávila P, Ferrer L, Soriano R, Diez M, Casabona J. Alto consumo de drogas recreativas y conductas sexuales de riesgo en hombres que tienen relaciones sexuales con hombres. Med Clin (Barc). 2015;145:102-7.

9. Methy N, Velter A, Semaille C, Bajos N. Sexual behaviours of homosexual and bisexual men in France: a generational approach. PLoS One. 2015;10(3):e0123151.

10. Methy N, Meyer L, Bajos N, Velter A. Generational analysis of trends in unprotected sex in France among men who have sex with men: The major role of ontext-driven evolving patterns. PLoS One. 12(2):e0171493. https:// doi.org/10.1371/journal.pone.0171493.

11. Velter A, Saboni L, Sommen C, Bernillon P, Bajos N, Semaille C. Sexual and prevention practices in men who have sex with men in the era of combination HIV prevention: results from the Presse Gays et Lesbiennes survey, France, 2011. Euro Surveill. 2015;20(14):21090. Available online:http:// www.eurosurveillance.org/ViewArticle.aspx?Articleld=21090.

12. Beltzer N, Saboni L, Sauvage C, Lydié N, Semaille C, Warszawski J; group KABP France. An 18-year follow-up of HIV knowledge, risk perception, and practices in young adults. AIDS. 2013;27:1011-9.

13. Casalino E, Choquet C, Leleu A, Hellmann R, Wargon M, et al. Trends in Condom Use and Risk Behaviours after Sexual Exposure to HIV: A SevenYear Observational Study. PLoS One. 2014;9(8):e104350. https://doi.org/10. 1371/journal.pone.0104350.

14. Benson LS, Martins SL, Whitaker AK. Correlates of heterosexual anal intercourse among women in the 2006-2010, National Survey of family growth. J Sex Med. 2015;12(8):1746-52. https://doi.org/10.1111/jsm.12961.

15. Mercer $\mathrm{CH}$, Tanton C, Prah P, Erens B, Sonnenberg P, Clifton S, et al. Changes in sexual attitudes and lifestyles in Britain through the life course and over time: findings from the National Surveys of sexual attitudes and lifestyles. Lancet. 2013;382(9907):1781-94.

16. Hess KL, Crepaz N, Rose C, Purcell D, Paz-Bailey G. Trends in sexual behavior among men who have sex with men (MSM) in high-income countries, 1990-2013: a systematic review. AIDS Behav. 2017;21(10):2811-34.

17. Chen YH, Snowden JM, McFarland W, Raymond HF. Pre-exposure prophylaxis (PrEP) use, Seroadaptation, and sexual behavior among men who have sex with men, San Francisco, 2004-2014. AIDS Behav. 2016;20(12):2791-7.

18. Paz-Baileya G, Mendozaa MCB, Finlaysona T, Wejnerta C, Lea B, Rosea C, et al. Trends in condom use among MSM in the United States: the role of antiretroviral therapy and seroadaptive strategies. AIDS. 2016;30:1985-90.

19. ECDC. The EMIS Network. EMIS 2010: The European Men-Who-Have-SexWith-Men Internet Survey. Findings from 38 countries. Stockholm: European Centre for Disease Prevention and Control, 2013. Stockholm: ECDC; 2010. Report No.: ISBN 978-92-9193-458-4

20. Desai S, Brown AE, Mitchell H, Hughes G, Delpech V. An overview of the HIV epidemic among men who have sex with men in the United Kingdom, 1999-2013. Euro Surveill. 2015;20(14):5-13.

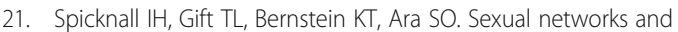
infectiontransmission networks among men who have sex with men as causes of disparity and targets of prevention. Sex Transm Infect. 2017;0:1-2.

22. Ndowa F, Lusti-Narasimhan M. The threat of untreatable gonorrhoea: implications and consequences for reproductive and sexual morbidity. Reprod Health Matters. 2012;20(40):76-82.

23. Daskalopoulou M, Rodger Alison J, Phillips Andrew N, Sherr L, Elford J, McDonnell Jy, et al. Condomless sex in HIV-diagnosed men who have sex with men in the UK: prevalence, correlates, and implications for HIV transmission. Sex Transm Infect. 2017;0:1-9.

24. Holt M, Lea T, Asselin J, Hellard M, Prestage G, Wilson D, et al. The prevalence and correlates of undiagnosed HIV among Australian gay and 
bisexual men: results of a national, community-based, bio-behavioural survey. J Int AIDS Soc. 2015;18:1-8.

25. Marrazzo JM, Dombrowski JC, Mayer KH. Sexually transmitted infections in the era of antiretroviral-based HIV prevention: Priorities for discovery research, implementation science, and community involvement. PLoS Med. 2018;15(1): e1002485. https://doi.org/10.1371/journal.pmed.1002485 eCollection 2018 Jan.

26. Golden MR, Handsfield HH. Preexposure prophylaxis to prevent bacterial sexually transmitted infections in men who have sex with men. Sex Transm Dis. 2015;18(2):104-5.

\section{Publisher's Note}

Springer Nature remains neutral with regard to jurisdictional claims in published maps and institutional affiliations.

Ready to submit your research? Choose BMC and benefit from:

- fast, convenient online submission

- thorough peer review by experienced researchers in your field

- rapid publication on acceptance

- support for research data, including large and complex data types

- gold Open Access which fosters wider collaboration and increased citations

- maximum visibility for your research: over $100 \mathrm{M}$ website views per year

At $\mathrm{BMC}$, research is always in progress.

Learn more biomedcentral.com/submissions 